\title{
Allozymic variation in the European polecat Mustela putorius from western France
}

\author{
Thierry LODÉ
}

\begin{abstract}
Lodé T. 1999. Allozymic variation in the European polecat Mustela putorius from western France. Acta Theriologica 44: 215-218.

Allozymic variation was surveyed in 21 European polecats Mustela putorius Linnaeus, 1758 from western France, using starch gel electrophoresis. Fourteen loci were successfully examined and genetic variation was detected at $28.6 \%$ of the loci at the 0.05 level. Heterozygosity level averaged 0.082 . European polecats from western France clearly showed significant levels of genetic variability. This result contrasts with previously reported analyses from Danish populations.
\end{abstract}

Laboratoire d'Ecologie Animale, U.F.R. Sciences, Université d'Angers, 49045 Angers, France, e-mail: thierry.lode@univ-angers.fr

Key words: Mustela putorius, allozyme electrophoresis, heterozygosity, genetic variation

\section{Introduction}

Comparative studies on genetic variability among mammals reported a supposed lower heterozygosity level in carnivores than in other groups (cf Nevo 1978, Allendorf et al. 1979, Sage et al. 1982, Simonsen 1982, Wooten and Smith 1985). One extreme example is the African cheetah Acinonyx jabatus which is known to show very little genetic variation (O'Brien et al. 1985).

Nevertheless, most of the studies only deal with few species or limited number of relatively localised populations. For instance, the Danish populations of carnivores examined by Simonsen (1982) revealed no allozymic variation within any studied species. By contrast, Lidicker and McCollum (1997) detected $19.4 \%$ of polymorphic loci in sea otter Enhydra lutris populations from Alaska and California. In the same way, Mitton and Raphael (1990) surveying only 10 American marten Martes americana from Wyoming found genetic variations at $33 \%$ of the loci.

Although the chromosome number remains generally constant within the different carnivore families, Mustelidae exhibit some karyotypic variation which may result from Robertsonian processes (Wurster and Benirschke 1968). From a phylogenetic point of view, Mustelidae form a primitive but rather diverse family. Thereby, the "polecat" syngameon, according to the Templeton's definition (1989), may include together the European polecat Mustela putorius, the domestic ferret $M$. furo, the steppe polecat $M$. eversmanni and probably the European mink $M$. lutreola all of which are at least partially interfertile (Grafodatsky et al. 1978, Ternovskaya 1990), despite karyological differences. In this syngameon, the divergence of the species tends to be correlated with different ecological niches 
(Youngman 1982). Polecat populations are widespread in the Palearctic region and live in various habitats; therefore polecats may exploit diverse trophic ressources (cf Blandford 1987, Lodé 1997). Thus, it seems reasonable to suspect the existence of genetic variations paralleling such diversity among polecats.

I report here allozymic variations in a polecat Mustela putorius Linnaeus, 1758 population from western France.

\section{Material and methods}

The genetic analysis is based on 21 European polecats Mustela putorius (14 females and 7 males) from western France sampled between Brittany and Poitou. The studied animals were road-killed polecats; only fresh individuals were opportunistically collected since 1995 (authorisation DPN 95-97), and stored at $-22^{\circ} \mathrm{C}$ in the laboratory.

Muscle tissue samples were removed from back limbs and analysed by horizontal starch gel electrophoresis using standard techniques (Selander et al. 1971). About $1 \mathrm{~g}$ of tissue was homogenised and centrifuged. I successfully investigated 11 enzymatic protein encoded by 14 putative loci: adenylate kinase (E.C. 2.7.4.3, $A k$ ); esterases (E.C. 3.1.1.1, Est, Est-2), fructose diphosphatase (E.C. 3.1.3.11, $F d p$ ), glucose-phosphate isomerase (E.C. 5.3.1.9, Gpi); lactate dehydrogenase (E.C. 1.1.1.27, Ldh-1, $L d h$-2), malate dehydrogenase (E.C. 1.1.1.37, Mdh-1, Mdh-2); malic enzyme (E.C. 1.1.1.40, Me); mannose phosphate isomerase (E.C. 5.3.1.8, Mpi); phosphoglucomutase (E.C. 2.7.5.1, Pgm-2), purine nucleoside phosphorylase (E.C. 2.4.2.1, $N p$ ); superoxide dismutase (E.C. 1.15.1.1, Sod). The continuous buffer systems employed were Tris-citrate $\mathrm{pH} 6$ and Tris EDTA Borate. Zones of enzymatic activity detected on the gels were called $\mathrm{F}$ (fast) or $\mathrm{S}$ (slow) considering their mobility from the most anodal and numbered sequentially for each allele.

Genotypic and allelic frequencies were determined by direct counts from allozyme phenotypes. The mean observed heterozygosity level was averaged over loci and the mean unbiased heterozygosity level was calculated as $H^{\prime}=\Sigma\left[2 n\left(1-\Sigma \mathrm{p}_{i}{ }^{2}\right) /(2 n-1)\right] / r$, where $n$ is the number individuals, $\mathrm{p}_{i}$ the frequency $i$ th allele at a locus, and $r$ the number of successfully investigated loci (Nei 1978).

\section{Results and discussion}

Among 21 polecats from western France, 5 of 14 examined loci were polymorphic loci whereas 9 appeared to be monomorphic but only four loci were polymorphic at the 0.05 level. Thus the proportion of polymorphic loci was $35.7 \%$ of studied loci but only $28.6 \%$ at the 0.05 level.

Smith et al. (1978) documenting 42 species found an average of $20 \%$ of polymorphic loci (range of $3 \%$ to $62.5 \%$ ). Thus, this polecat population showed levels of allozymic variability comparable or slightly above that of other mammals. The polecat polymorphism averaged a similar level to that of one population of American martens Martes americana from Wyoming (33.3\%, 24 loci, Mitton and Raphael 1990). Of 31 loci scored, only $19.4 \%$ were polymorphic in Sea otter Enhydra lutris populations (Lidicker and McCollum 1997), and the Italian population of gray wolf Canis lupus only showed $10 \%$ of polymorphic loci (Randi et al. 1993). Nevertheless, since only 14 loci were considered here, it is possible that the pattern observed among polecats might be different with more loci examined. This estimate provides however new information about unsuspected levels of allozymic variations in polecats. 
Table 1. Genotypic and allelic frequencies for 5 polymorphic loci in 21 polecats from western France (S - slow, F - fast), ( $p$ and $q$ respectively refer to fast and slow electrophoretic mobilities).

\begin{tabular}{|c|c|c|c|c|c|c|}
\hline Locus & Genotype & $n$ & $\begin{array}{c}\text { Observed } \\
\text { frequencies }\end{array}$ & $\begin{array}{l}\text { Heterozygosity } \\
\quad\left(1-\Sigma \mathrm{p}_{i}{ }^{2}\right)\end{array}$ & $\begin{array}{c}\text { Allelic } \\
\text { frequencies }\end{array}$ & $\begin{array}{l}\text { Standard } \\
\text { deviation }\end{array}$ \\
\hline \multirow[t]{3}{*}{ Est-2 } & SS & 0 & 0.0000 & 0.0465 & $p=0.976$ & 0.007 \\
\hline & SF & 1 & 0.0476 & & $q=0.024$ & \\
\hline & $\mathrm{FF}$ & 20 & 0.9524 & & & \\
\hline \multirow[t]{3}{*}{$M d h-1$} & SS & 7 & 0.3333 & 0.4819 & $p=0.405$ & 0.023 \\
\hline & SF & 11 & 0.5238 & & $q=0.595$ & \\
\hline & FF & 3 & 0.1429 & & & \\
\hline \multirow[t]{3}{*}{$M e$} & SS & 14 & 0.6667 & 0.3084 & $p=0.191$ & 0.018 \\
\hline & SF & 6 & 0.2857 & & $q=0.809$ & \\
\hline & $\mathrm{FF}$ & 1 & 0.0476 & & & \\
\hline \multirow[t]{3}{*}{$N p$} & SS & 7 & 0.3333 & 0.4819 & $p=0.595$ & 0.023 \\
\hline & $\mathrm{SF}$ & 3 & 0.1429 & & $q=0.405$ & \\
\hline & $\mathrm{FF}$ & 11 & 0.5238 & & & \\
\hline \multirow[t]{3}{*}{ Pgm-2 } & SS & 18 & 0.8571 & 0.1326 & $p=0.071$ & 0.012 \\
\hline & $\mathrm{SF}$ & 3 & 0.1429 & & $q=0.929$ & \\
\hline & $\mathrm{FF}$ & 0 & 0.0000 & & & \\
\hline
\end{tabular}

Here, polymorphic loci were Est-2, Mdh-1, Me, Np and Pgm-2 and two alleles were found in each locus (Table 1). Enzymatic activity revealed two independent isozymes for the $M d h$ and only the fastest one (Mdh-1) was found polymorphic. This locus was also polymorphic in American marten (Mitton and Raphael 1990). Similarly, Est-2 and Pgm-2 were polymorphic both in polecat and in marten (Mitton and Raphael 1990).

Genotypic frequencies are given for the five polymorphic loci in Table 1. Only one individual was polymorphic for the Est-2 showing the lowest level of heterozygosity. At this locus, the FF homozygotes prevailed in populations. By contrast, observed heterozygosity reached 0.524 for the $M d h-1$ locus. The SS genotype was predominant at the Pgm-2 locus and the other allele was only observed in heterozygotes.

The mean heterozygosity level for the 14 studied loci was $H=0.082$ and the standardized heterozygosity level was $H^{\prime}=0.106$. Both estimates of heterozygosity clearly exceeded the mean heterozygosity value of 0.039 reported by Wooten and Smith (1985) for 138 mammalian species. However, the $H$ estimate is below the mean heterozygosity averaging 0.167 in Martes americana (Mitton and Raphael 1990).

Although our sample originated from a restricted geographical area, the polecats showed a high level of allozymic variability in western France. This result underlines that Mustelids are able to reveal higher levels of genetic variability than previously suggested from Danish populations (Simonsen 1982). In terms of biological conservation, maintenance of high level of genetic variability might be an essential element to preserve polecat populations. 
Acknowledgements: I thank D. Le Jacques and O. Grosselet for their help. D. Guerineau, D. Lacourpaille, A. Le Beller, D. Montford, A. Pihuit and J. Pourreau provided valuable assistance in collecting data.

\section{References}

Allendorf F. W., Christiansen F. B., Dobsen T., Eames W. F. and Freydenberg O. 1979. Electrophoretic variation in large mammals. I. The polar bear, Thalarctos maritimus. Hereditas 91: 19-22.

Blandford P. R. S. 1987. Biology of the Polecat Mustela putorius: a literature review. Mammal Review 17: $155-198$.

Grafodatsky A. S., Ternovskaya Y. G., Ternovsky D. V. and Radzhabli S. I. 1978. Cytogenetics of albinism in ferrets of the genus Putorius (Carnivora, Mustelaidae). Genetika 14: 68-71.

Lidicker W. Z. Jr and McCollum F. C. 1997. Allozymic variation in California sea otters. Journal of Mammalogy 78: 417-425.

Lodé T. 1997. Trophic status and feeding habits of the European Polecat Mustela putorius L. 1758. Mammal Review 27: 177-184.

Mitton J. B. and Raphael M. G. 1990. Genetic variation in the marten, Martes americana. Journal of Mammalogy 71: 195-197.

Nei M. 1978. Estimation of average heterozygosity and genetic distance from a small number of individuals. Genetics 89: 583-590.

Nevo E. 1978. Genetic variation in natural populations: patterns and theory. Theorical Population Biology 13: 121-177.

O'Brien S. J., Wildt D. E., Goldman D., Merril C. R. and Bush M. 1985. Genetic basis for species vulnerability in the cheetah. Science 227: 1428-1434.

Randi E., Lucchini V. and Francisci F. 1993. Allozyme variability in the Italian wolf (Canis lupus) population. Heredity 71: 516-522.

Sage V., Allendorf F. W., Eanes W. F. and Kapel F. O. 1982. Electrophoretic variation in large mammals. III. The ringed seal, Pua hispida, the harp seal, Pagophilus groenlandica, and the hooded seal, Cystophora cristata. Hereditas 97: 87-90.

Selander R. K., Smith M. H., Yang S. Y., Johnson W. E. and Gentry J. B. 1971. Biochemical polymorphism and systematics in the genus Peromyscus. I. Variation in the old-field mouse (Peromyscus polionotus). University of Texas Studies in Genetics 6: 49-90.

Simonsen V. 1982. Electrophoretic variation in large mammals. II. The red fox, Vulpes vulpes, the stoat, Mustela erminea, the weasel, Mustela nivalis, the polecat, Mustela putorius, the pine marten, Martes martes, the beech marten, Martes foina, and the badger, Meles meles. Hereditas 96: 299-305.

Smith M. H., Manlove M. N. and Joule J. 1978. Spatial and temporal dynamics of genetic organisation of small mammal populations. [In: Populations of small mammals under natural conditions. D. P. Snyder, ed]. University of Pittsburgh, Pittsburg: 1-237.

Templeton A. 1989. The meaning of species and speciation: a genetic perspective. [In: Speciation and its consequences. D. Otte and J. A Endler, eds]. Sinauer: 2-17.

Ternovskaya Y. G. 1990. Natural and experimental hybridization in Mustelidae. 5th Congress of the all Union Theriological Society, Moscow: 94-95.

Wooten M. C. and Smith M. H. 1985. Large mammals are genetically less variable? Evolution 39: 210-212.

Wurster D. H. and Benirschke K. 1968. Comparative cytogenic studies in the Order Carnivora. Chromosoma 24: 336-382.

Youngman P. M. 1982. Distribution and systematics of the European mink Mustela lutreola Linnaeus 1761. Acta Zoologica Fennica 166: 1-48.

Received 19 November 1997, accepted 12 November 1998. 